Palabra Clave (La Plata), octubre 2017, vol. 7, n 1, e041. ISSN 1853-9912

Universidad Nacional de La Plata.

Facultad de Humanidades y Ciencias de la Educación.

Departamento de Bibliotecología

\title{
Indexação de obras de ficção em bibliotecas: avaliação e adequação do Modelo para Indexação de Ficção (MENTIF)
}

\author{
Indexing of works of fiction in libraries: evaluation and \\ adequacy of the Model for Fiction Indexing (MENTIF)
}

\section{Mariângela Spotti Lopes Fujita *, Deise Maria Antonio Sabbag **, Luciana Beatriz Piovezan dos Santos *, Rosane Rodrigues de Barros Ribas *, Fábio Sampaio Rosas *, Márcia Correia Bueno Degasperi *}

* Universidade Estadual Paulista (UNESP), Brasil, ** Universidade de São Paulo (USP),

Brasil | fujita@marilia.unesp.br

\section{PALAVRAS-CHAVE}

Metodologia de indexação

Obras de ficção

Bibliotecas universitárias

\section{RESUMO}

A indexação de obras de ficção para catálogos de bibliotecas necessita de metodologia apropriada à estrutura textual de narrativa de ficção. A falta de uma metodologia de indexação limita a representação e recuperação de assuntos no catálogo. A proposta metodológica do Modelo de Indexação de ficção (MENTIF) amplia pontos de acesso de assunto aos registros bibliográficos na recuperação desses conteúdos por outros termos diferentes da representação de forma "literatura de ficção". A investigação sobre indexação de obras de ficção tem como objetivo o relato da avaliação e adequação do Modelo para Indexação de Ficção (MENTIF) realizada por pesquisadores e catalogadores. Para isso foram realizadas quatro etapas de avaliação que incluíram análise de registros bibliográficos e aplicação de questionários para levantamento de dados sobre satisfação e insatisfação. Os resultados obtidos proporcionaram a adequação do MENTIF conforme estratégias cognitivas e sociocognitivas dos profissionais catalogadores e em função da restrição de tempo para a tarefa.

\section{KEYWORDS ABSTRACT}

Indexing methodology

Works of fiction University libraries 


\section{Introdução}

As bibliotecas universitárias têm coleções em áreas de conhecimento especializadas diversas tais como física, química, odontologia ou literatura, dentre outras, mas verificamse em todas essas coleções as denominadas obras de ficção que, mesmo não fazendo parte de uma coleção especializada em física, por exemplo, existem para atender o interesse de leitura de lazer do usuário. Em uma coleção da área de literatura, o catalogador tem familiaridade para a indexação de conteúdos especializados, mas com obras de ficção a dificuldade em representar o conteúdo é a mesma que teria o catalogador da coleção de física ou de odontologia. Tais dificuldades estão relacionadas às características textuais desses conteúdos com narrativas ficcionais. A falta de uma metodologia de indexação limita a exaustividade da representação desses conteúdos aos termos sem especificidade, que pouco recuperam em uma busca ao catálogo.

A proposta metodológica do Modelo de Indexação de Ficção - MENTIF - (Sabbag, 2017) foi apresentada em capacitação aos catalogadores de bibliotecas universitárias com o objetivo de ampliar pontos de acesso de assunto aos registros bibliográficos, para propiciar a recuperação desses conteúdos por outros termos diferentes da representação, de forma que invariavelmente ocorria para todos esses conteúdos pelo termo literatura de ficção seguido da nacionalidade brasileira ou inglesa ou outras. Conforme Sabbag (2017, p.19), o MENTIF "tem como objetivo contribuir para a realização da análise e síntese, etapas presentes no processo de indexação de itens documentários, especificamente de textos narrativos de ficção, ou simplesmente obras de ficção". Importante ressaltar que o modelo trabalha com narrativas em prosa, romances que apresentam macroestrutura, superestrutura e microestrutura, com tipologia começo, meio e fim, ou seja, não é aplicado a narrativas em versos e outras modalidades como, por exemplo, romances escritos no formato de carta.

Com a capacitação, os catalogadores foram orientados a realizar a indexação das obras de ficção e após período de 2 anos, o Grupo de Política de Indexação 1 definiu a avaliação de uma amostra de 336 registros bibliográficos indexados pelos catalogadores para verificar se a metodologia estava sendo aplicada e se haveria necessidade de adequação do modelo a partir de levantamento de satisfação e insatisfação. Dos 336 registros analisados, um terço (110 registros) não atendeu as orientações do MENTIF e dois terços dos registros atenderam o MENTIF por meio da atribuição de gênero literário e localização geográfica. Esse resultado e as discussões com os catalogadores do Grupo de Política de Indexação foram determinantes para a decisão de realizar a adequação do MENTIF e de suas orientações de uso. Para isso, foi necessário o desenvolvimento de métodos de avaliação que proporcionaram a adequação do MENTIF conforme estratégias cognitivas e sociocognitivas dos profissionais catalogadores e em função da restrição de tempo para a tarefa.

A investigação sobre indexação de obras de ficção tem como objetivo o relato da avaliação e adequação do MENTIF, realizada por pesquisadores e catalogadores de bibliotecas com a finalidade de demonstrar a interação dialógica entre teoria e prática profissional, e as contribuições para a criação de novas metodologias com inovação e relevância para a gestão da informação no que tange ao tratamento temático. 


\section{Indexação de obras de ficção e o modelo metodológico}

As linguagens de indexação, bem como os esquemas de classificação bibliográfica e outros sistemas de organização e representação do conhecimento, são construções sociais que sofrem transformações culturais ao longo do tempo. Desta forma, a mudança no tratamento de disciplinas e assuntos está sujeita a alterações que relacionam o que é representado e o que não é representado.

Especificamente no que diz respeito a obras de ficção, Rafferty (2001) em seus estudos concluiu que a análise e a indexação de obras de ficção apresentam historicamente uma relação empobrecida que começa a mudar com o surgimento de alguns sistemas de recuperação inovadores. Estes buscam tratar justamente as questões de significado e análise em obras de ficção. Como exemplo, o autor apresenta o projeto escandinavo Bookhouse (tendo como objetivo otimizar as possibilidades comuns para o acesso do conteúdo de ficção escandinava) que teve como objetivos a contribuição para o aumento da mediação, o estabelecimento de princípios comuns de indexação da ficção, e o desenvolvimento do Bookhouse para funcionar como um OPAC escandinavo para a recuperação da ficção.

García-Marco et al. (2010) corroboram com essa questão ao dizer que os textos narrativos de ficção estão recebendo espaço considerável nas disciplinas, na educação, com os recursos de multimídia, também na psicologia e áreas como a de negócios, gestão, marketing, cultura corporativa e políticas.

Nos últimos trinta anos, vários estudos voltados para a representação dos textos narrativos de ficção são encontrados na área de Ciência da Informação. Eriksson (2005) presume que este interesse de estudo não surgiu nas últimas décadas, e aponta como primeiro artigo sobre o assunto o "The Classification of fiction", de Ernest Baker (1899). A classificação de ficção de Baker foi desenvolvida com método hierárquico com o objetivo de proporcionar ao usuário quais seriam as melhores obras para leitura.

$\mathrm{Na}$ área de Ciência da Informação encontramos várias pesquisas que têm como preocupação a representação das obras de ficção, dentre elas: Burgess (1936), Spiller (1980), Pejtersen e Austin (1983), Harrel (1985),Beghtol (1986), Jansson e Sodervall (1987), Macpherson (1987), Beghtol (1989), Bell (1991), Olderr (1991),Ranta (1991), Hayes (1992), Beghtol (1992), Beghtol (1994a), Negrini (1995), Andersson e Holst (1996), Hidderley e Rafferty (1997), Nielson (1997), Saarti (1997), Beghtol (1997), Saarti (1999a, 1999b, 2002). Os temas mais pesquisados por estes autores foram: sistema de classificação para obras de ficção; como prover a recuperação da informação de ficção; a construção de tesauros para ficção; a indexação de obras de ficção e a construção de catálogos.

Em âmbito brasileiro, Sabbag (2013) desenvolveu um modelo metodológico para análise de obras de ficção (MENTIF). Para a autora, o desenvolvimento deste modelo foi necessário para suprir uma lacuna na área de análise documental que, tradicionalmente, apresenta como foco de estudos e representação os textos científicos; também para desautomatização de procedimentos e da substituição dos processos intuitivos por procedimentos metodologicamente adequados conforme apontam Guimarães, Moraes e Guarino (2007, p. 95) quando dizem que "que o profissional sabe, intuitivamente, a 
diferença entre um texto científico e um texto narrativo de ficção", mas é necessário um esforço de desautomatização já que "a literatura tradicional da área de análise documentária tem dedicado seus maiores esforços no delineamento dos procedimentos metodológicos aplicáveis ao texto científico".

Neste sentido cabe a pergunta por que empreender esforços em representar os assuntos das obras de ficção? Para responder essa questão dialogamos com três autores: Lancaster (2004), Beghtol (1994) e Moraes (2011).

O primeiro, Lancaster (2004) faz referência aos textos de ficção ao dizer que a indexação de obras de ficção apresenta problemas que diferem da indexação de um documento de não-ficção, já que os dois têm objetivos diferentes. Para o autor, o primeiro serve para entreter, suscitar emoções, divertir, "o segundo, fundamentalmente, para veicular informações. O fato de o segundo tipo poder, de vez em quando, entreter é igualmente fortuito em relação ao objetivo principal do veículo de comunicação" (Lancaster, 2004, p. 200).

Nessa direção, mas demonstrando outra perspectiva sobre o assunto, Beghtol (1994) explicita a distinção entre ficção e não-ficção dizendo que no mundo dos documentos podemos dividir as obras que "surgem a partir da imaginação de seus criadores e aquelas que surgem a partir de uma faculdade racional" (Beghtol, 1994, p. 7). Para a autora, as obras de ficção são escritos em prosa narrativa que pode ser tomada de forma ampla incluindo vários discursos.

Moraes (2011) em seus estudos sobre indexação de obras de ficção analisa as definições propostas por Lancaster (2004) e por Beghtol (1994) chegando à conclusão que a definição do primeiro autor sobre a obra literária é redutora, o que pode ser interpretado como desconhecimento em relação às manifestações literárias quando afirma que os textos de ficção destinam-se a entreter, suscitar emoções, divertir, etc.

Para os autores García-Marco et al. (2010), Lancaster (2004) desconsidera a questão nuclear da ficção que é a ficção como manifestação artística que transmite informação cultural. Os autores pontuam que em todas as civilizações a ficção é uma manifestação artística importante que serve como fonte de informação ao longo da história (GarcíaMarco et al., 2010).

Este reducionismo acerca da definição de Lancaster (2004) é contraposto por Moraes (2011) quando o pesquisador apresenta a amplitude na definição de Beghtol (1994) quanto ao texto de ficção. Para a autora ficção é narrative prose, com isso, uma grande quantidade de textos que não são apenas narrativos, mas podem ser classificados como ficcionais, não são contemplados. Para explicar essa questão, Moraes (2011) apresenta o exemplo de três épicos: Odisseia, Eneida e os Lusíadas. Trata-se de narrativas com microestrutura, macroestrutura e superestrutura, mas não são textos escritos em prosa, mas em verso.

Para construir uma definição de texto de ficção que seja mais adequada aos estudos voltados para a área de Ciência da Informação, Moraes (2011) toma como ponto de partida afirmações de Beghtol (1994) sobre uma autocrítica a sua definição de ficção. Dessa forma, como em Moraes (2011), entende-se que ficção é uma forma de arte, uma 
manifestação artística construída com palavras que ultrapassam os escritos originários da imaginação do escritor, pois pode conter elementos concretos da realidade. Portanto, o texto narrativo de ficção é uma manifestação artística que compreende microestruturas (elementos que indicam ações e mudanças de estado), macroestrutura (presença de personagens em situações que demandam mudanças de estado) e superestruturas (demarcadas por sequências de ações).

Considerar o texto narrativo de ficção como manifestação artística, como obra de arte, é voltar um olhar totalmente novo a esta manifestação textual, no que diz respeito à analise documental. É considerar que sua interação e interlocução atuam de um modo peculiar no desenvolvimento da competência comunicativa do analista. Essa competência comunicativa proporcionará um tipo específico de interação com o leitor-analista, indexador, catalogador: interação com uma criação artística, com uma forma artística, com uma expressão artística.

Nesse contexto teórico reflexivo é que Sabbag (2013) desenvolveu seu modelo para indexação de obras de ficção, tendo como subsídios teóricos as categorias propostas por Clare Beghtol (1994b) e a teoria do percurso gerativo de sentido (Fiorin, 2011). Considerando que as etapas do processo de análise documentária são a análise e a síntese, o MENTIF foi criado para ser utilizado pelo indexador/catalogador na primeira parte do processo, a análise, especificamente nas subetapas de leitura técnica do documento e identificação de conceitos, para que a obra de ficção receba uma representação adequada do seu assunto, extrapolando os indicadores históricos e geográficos que são utilizados para indexar essas obras.

O MENTIF caracteriza-se como um modelo de análise cognitivo onde o indexador/catalogador deve realizar a leitura técnica do documento buscando extrair os conceitos por meio de quatro categorias consideradas fundamentais para a obra de ficção: o personagem, o evento, o espaço e o tempo.

Tradicionalmente na área de Ciência da Informação empregam-se para a leitura técnica de documentos, estratégias importantes como: ler o título das obras, os subtítulos, a introdução e conclusão, frases introdutórias de parágrafos e capítulos, legendas de ilustrações, gráficos, tabelas, diagramas e suas explicações, palavras ou grupos de palavras. Essas estratégias mostram-se eficazes em documentos que oferecem uma estrutura textual e física adequada para a aplicabilidade dessa leitura (como em artigos científicos, relatórios técnicos, livros didáticos, etc.), mas quando as mesmas estratégias são aplicadas para a leitura técnica de obras de ficção, os resultados não são tão eficazes, sendo restritos à identificação da língua em que o documento foi escrito, seu gênero e sua nacionalidade. Evidentemente que os termos de indexação que representam a obra por língua, gênero e nacionalidade são importantes, mas não evidenciam o conteúdo, o assunto do texto de ficção.

Então surge a questão: como analisar e representar o assunto das obras de ficção? Uma solução seria a leitura integral das obras, mas devido a questões de tempo o profissional não dispõe dessa possibilidade. Diante disso, qual recurso estratégico de leitura o indexador/catalogador deve utilizar para a leitura de obras de ficção? A obra de ficção é uma modalidade de texto narrativo composto por estruturas superficiais, profundas e 
superestruturais. O texto narrativo de ficção possui um plano de conteúdo chamado de percurso gerativo de sentido que lhe confere concepção de conteúdo organizado em articulações narrativas, ou seja, ele possui um plano para sua construção, uma constante estrutura de base (Tatit, 2007). Esse percurso gerativo de sentido é definido por patamares (níveis) que, de acordo com Fiorin (2011), são: narrativo, discursivo e da manifestação. No nível narrativo encontramos a chamada sequência canônica, composta por quatro fases importantes para o encadeamento da narrativa: manipulação (um sujeito age sobre outro para levá-lo a querer e/ou dever fazer alguma coisa); a competência (o sujeito que realiza a narrativa é dotado de um saber e/ou poder fazer); performance (fase da transformação da narrativa); e sanção (última fase onde acontece a constatação de que a performance se concretizou e o reconhecimento do sujeito que operou a transformação). Seguindo a teoria do percurso gerativo de sentido poderíamos identificar o assunto de uma obra de ficção ao lermos a cadência narrativa presente na fase da performance e da sanção que, geralmente, estão presentes nos últimos capítulos das obras.

O MENTIF utiliza a teoria do percurso gerativo de sentido e propõe, como estratégia fundamental, a leitura técnica em obras de ficção dos últimos capítulos do livro; usando essa estratégia o indexador/catalogador não necessitará realizar a leitura integral do documento. Dessa forma, o modelo propõe que o indexador/catalogador examine as obras de ficção utilizando como estratégias de leitura as seguintes partes do documento: a) título das obras; b) subtítulos; c) resumos; d) sumário; e) ilustrações, diagramas, tabelas e títulos explicativos (não são comuns em textos narrativos de ficção), e f) conclusão: composta pelos últimos capítulos das obras.

Para a subetapa da identificação dos conceitos, o MENTIF utiliza quatro categorias consideradas generalizantes para obras de ficção. Essas categorias foram sugeridas por Begthol (1994b) em seu livro The classification of fiction: the development of system based on theoretical principles, onde a autora busca um caminho para realizar a análise dessas obras, pois não aceita a visão de que textos de ficção são intratáveis, não fluídos para análise por serem considerados destituídos de elementos constantes para uma análise suficiente e confiável.

Neste sentido, a autora destaca que as obras de ficção apresentam histórias com elementos constantes onde se têm eventos e coisas existentes, ou seja, personagens e cenários. Também utiliza dois estudos que descrevem categorias para análise de obras de ficção. O primeiro estudo foi de Brewer (1984), que compara as convenções narrativas em histórias orais e escritas com o objetivo de formular hipóteses sobre a existência de elementos universais em textos narrativos de ficção. O fruto deste trabalho é a proposição de cinco elementos que seriam universais para obras de ficção: cenário, personagens, eventos, resolução e narrados. O segundo estudo foi realizado por Ruthrof (1981) que propõe que a narrativa contém oito categorias: tempo, espaço, personagem, atos, eventos, aspectos pessoais, aspectos atmosféricos, e padrões ideológicos. Beghtol (1994b) compara as duas propostas de categorização com o objetivo de analisar o nível de generalização e o processo sistemático de divisão, e sugere quatro categorias aceitas como fundamentais para ficção. 
Tendo como embasamento teórico o trabalho de Beghtol (1994b), o MENTIF propõe a análise das quatro categorias fundamentais para ficção onde:

- personagem (inclui o narrador): são seres e atores que existem e participam no mundo da ficção;

- evento (inclui atos de humanos e não humanos): ocorrências e acontecimentos do mundo real e não real;

- espaço: lugares geográficos e localizações no mundo ficcional;

- tempo: unidade de tempo no mundo ficcional.

No ano de 2014 foram oferecidos aos catalogadores da Universidade Estadual Paulista "Júlio de Mesquita Filho" (São Paulo/Brasil) dois cursos de capacitação para indexação de textos narrativos de fiç̧ão utilizando o modelo MENTIF. Na ocasião, os profissionais realizaram exercícios práticos com estratégias de leitura técnica específicas para obras de ficção e preenchendo o quadro categorias, a seguir:

\section{Quadro 1. Modelo metodológico para análise de obra de ficção (MENTIF)}

\begin{tabular}{|l|l|l|l|}
\hline Categorias & \multicolumn{1}{|c|}{ Perguntas } & Conceitos & Termos de Indexação \\
\hline Personagem & $\begin{array}{l}\text { Existem seres ou atores que } \\
\text { existem e participam no mundo } \\
\text { da ficção (inclui o narrador } \\
\text { quando for o caso)? }\end{array}$ & & \\
\hline Evento & $\begin{array}{l}\text { Existem ocorrências e } \\
\text { acontecimentos do mundo real e } \\
\text { não real (inclui atos humanos e } \\
\text { não humanos)? }\end{array}$ & & \\
\hline Espaço & $\begin{array}{l}\text { A narração acontece em um } \\
\text { determinado lugar geográfico ou } \\
\text { localização no mundo ficcional? }\end{array}$ & & \\
\hline Tempo & $\begin{array}{l}\text { Existe uma unidade de tempo no } \\
\text { mundo ficcional? }\end{array}$ & & \\
\hline
\end{tabular}

Fonte: Sabbag, 2013

Em 2017, o modelo MENTIF passou a compor o Manual de Política de Indexação para Bibliotecas Universitárias da Unesp (Universidade Estadual Paulista - Unesp, 2017). No âmbito da Unesp o modelo destina-se aos bibliotecários que realizam a indexação/catalogação de obras de ficção. No manual de política de indexação encontramos os passos que devem ser considerados para efetiva aplicação do MENTIF (Sabbag, 2017):

1. Identificação da tipologia textual: reconhecimento por parte dos bibliotecários das estruturas textuais presentes no texto narrativo de ficção, estruturas que diferenciam esse tipo de recurso bibliográfico dos demais presentes na biblioteca, solicitando estratégias específicas para sua análise;

2. Leitura documentária: para a leitura documentária de textos narrativos de ficção, o bibliotecário deve considerar as seguintes partes estruturais: título, subtítulo (se 
houver), resumo, sumário, ilustrações, diagramas, tabelas e títulos explicativos. Por se tratar de uma obra literária, a leitura documentária dessas partes pode-se mostrar insuficiente; diante dessa questão, o MENTIF propõe que o bibliotecário leia na íntegra o capítulo de conclusão, e quando este não trouxer as informações necessárias o penúltimo e o último capítulo. Dessa forma, a estratégia de leitura de textos narrativos de ficção deve considerar a leitura dos: a) título das obras; b) subtítulos; c) resumo; d) sumário; e) ilustrações, diagramas, tabelas e títulos explicativos (não são comuns em textos narrativos de ficção), e f) conclusão (composta pelos últimos capítulos das obras).

3. Identificação de conceitos: após a realização da leitura documentária do texto narrativo de ficção, o bibliotecário deve identificar quais são os conceitos presentes na obra que serão pertinentes para a indexação. Para essa etapa, o MENTIF propõe que o profissional analise as categorias personagem, evento, espaço e tempo, respondendo perguntas que possibilitem a extração dos conceitos;

4. Seleção de conceitos: nesta etapa, o bibliotecário deve selecionar os conceitos que foram extraídos na fase de identificação de conceitos;

5. Representação Documentária: o bibliotecário deve utilizar a Linguagem Unesp para realizar a indexação, os conceitos selecionados devem ser traduzidos na linguagem de indexação utilizada na instituição.

\section{Quadro 2. MENTIF: identificação de conceitos, seleção de conceitos e termos de indexação}

\begin{tabular}{|l|l|l|l|l|}
\hline Categorias & \multicolumn{1}{|c|}{ Perguntas } & Conceitos & $\begin{array}{c}\text { Seleção de } \\
\text { conceitos }\end{array}$ & $\begin{array}{l}\text { Termos de } \\
\text { indexação }\end{array}$ \\
\hline Personagem & $\begin{array}{l}\text { Existem seres ou atores que } \\
\text { existem e participam no } \\
\text { mundo da ficção (inclui o } \\
\text { narrador quando for o caso)? }\end{array}$ & & & \\
\hline Evento & $\begin{array}{l}\text { Existem ocorrências e } \\
\text { acontecimentos do mundo real } \\
\text { e não real (inclui atos humanos } \\
\text { e não humanos)? }\end{array}$ & $\begin{array}{l}\text { A narração acontece em um } \\
\text { determinado lugar geográfico } \\
\text { ou localização no mundo } \\
\text { ficcional? }\end{array}$ & & \\
\hline Espaço & $\begin{array}{l}\text { Existe uma unidade de tempo } \\
\text { no mundo ficcional? }\end{array}$ & & & \\
\hline Tempo & & & & \\
\hline
\end{tabular}

Fonte: Sabbag, 2017. 


\section{Avaliação do Modelo para Indexação de Ficção (MENTIF)}

Neste estudo, realiza-se uma pesquisa descritiva e analítica, fundamentada no referencial teórico-metodológico da Indexação e Catalogação de Assuntos.

O Universo da pesquisa é composto pelo acervo de obras de ficção das bibliotecas que integram a Rede de Bibliotecas da Universidade Estadual Paulista "Júlio de Mesquita Filho" - Unesp. Considerando a importância de indexação consistente desse tipo de obra, a avaliação do Modelo para Indexação de Ficção foi motivada pela verificação de sua aplicabilidade por catalogadores e da necessidade, ou não, de readequação para a realidade das bibliotecas da Unesp.

Para tanto, a avaliação consistiu metodologicamente em 4 etapas: na primeira analisaramse os registros bibliográficos não indexados e os indexados após capacitações aos catalogadores; na segunda foi realizada a aplicação de questionário para avaliar a satisfação e insatisfação dos catalogadores no uso do Modelo para Indexação de Ficção; a terceira e quarta etapa seguiram os moldes da primeira (análise dos registros) e segunda etapa (aplicação de questionário), mas dentro de um contexto pós readequação do MENTIF, a qual se fez necessária.

O desenvolvimento da primeira etapa de avaliação para análise dos registros bibliográficos foi realizado a partir da criação de um relatório dos registros bibliográficos catalogados e indexados no período de 12 meses para seleção de uma amostra. Para isso, efetuou-se busca na base de dados com os seguintes termos indexados nos campos de assunto: Literatura e Fiç̧ão, excluindo-se todos os registros que continham os termos História e crítica, e Teatro, por não serem considerados obras de ficção.

Foi recuperado um total de 3.462 registros, sendo 2.748 provenientes de catalogações novas, e 714 registros que haviam passado por revisão da indexação de acordo com o manual de política de indexação. Iniciou-se, a partir desse total recuperado, uma filtragem para a seleção da amostra para a avaliação com os seguintes critérios: desconsideraramse registros de filmes (pois a análise desse tipo de obra consiste em outro método), contos, poesias, crônicas e coletâneas (por conterem diversos temas em sua composição). Após essa filtragem, obteve-se um resultado de 1.355 registros, dos quais se decidiu utilizar $25 \%$, equivalente a 336 registros selecionados por sorteio on-line por meio do site http://www.sorteador.com.br.

A avaliação dos registros bibliográficos selecionados foi realizada conforme os critérios de: quantidade de termos no registro bibliográfico, de acordo com a exaustividade da política de indexação (Universidade Estadual Paulista Júlio de Mesquita Filho - Unesp, 2017), e especificidade dos termos atribuídos aos seguintes conceitos:

- Gênero e localização geográfica. Indexação que contenha, por exemplo: Literatura alemã, Literatura Brasileira, etc.;

- Gênero literário de ficção e localização geográfica. Exemplo de aplicação: Ficção alemã, Ficção brasileira, Ficção infanto-juvenil brasileira, etc.;

- Gênero de ficção específico. Exemplo de aplicação: Ficção policial, Ficção histórica, Histórias de amor, Histórias de aventuras, etc.;

- Temas (assuntos específicos) sem utilização da forma (ficção). Exemplo de aplicação: Budismo, Mulheres - Índia, etc.;

- Temas (assuntos específicos) com utilização da forma. Exemplo de 
aplicação: Budismo - Fiç̧ão, Mulheres - Índia - Ficção, etc.

A segunda etapa de avaliação consistiu na aplicação de questionário (Apêndice A) para obter informações sobre os procedimentos de indexação utilizados pelos catalogadores com uso do MENTIF: satisfação, insatisfação e dificuldades dos catalogadores durante a indexação das obras de ficção.

A terceira etapa consistiu na avaliação da aplicação experimental da versão adaptada do Modelo para Indexação de Ficção (MENTIF) (Apêndice B) realizada por 10 catalogadores que responderam o questionário da segunda etapa da avaliação e que tinham registros avaliados na primeira etapa. Foi solicitado que fizessem nova indexação dos registros que, anteriormente, não haviam obtido especificidade dos assuntos, para fins de comparação e verificação da aplicação do MENTIF. Cada catalogador ficou responsável por reindexar 5 registros bibliográficos.

Foram capturadas imagens dos registros escolhidos, conforme Figura 1, como parâmetro de comparação posterior.

\section{Figura 1. Imagem capturada do registro antes da reindexação}

\begin{tabular}{|ll|}
\hline ISBN & 9788535918700 \\
\hline Entrada Principal & Scliar, Moacyr,1937-2011. \\
\hline Título & 0 centauro no jardim / Moacyr Scliar. - \\
\hline Imprenta & São Paulo : Companhia de Bolso, 2011 \\
\hline Descrição & 218 p. \\
\hline Nota local & A biblioteca BAS possui a 3. reimpressão de 2013 \\
Assunto & Ficção brasileira. \\
\hline Assunto & Literatura brasileira. \\
\hline Assunto & Fabulas brasileiras. \\
\hline Assunto & Judeus na literatura. \\
\hline
\end{tabular}

Fonte: Catálogo da Unesp

Após a reindexação pelos catalogadores foram capturadas imagens atualizadas registros (Figura 2).

Figura 2. Imagem capturada do registro após da reindexação

\begin{tabular}{|c|c|}
\hline Data atualizacosolo & 20170503150544.0 \\
\hline ISBN & 9788535918700 \\
\hline Entrada Principal & Scliar, Moacyr,1937-2011. \\
\hline Titulo & O centauro no jardim / Moacyr Sdiar. - \\
\hline Imprenta & São Paulo : Companhia de Bolso, 2011 \\
\hline Descriçâo & $218 \mathrm{p}$. \\
\hline Nota local & A biblioteca BAS possui a 3. reimpressāo de 2013 \\
\hline Assunto & Literatura brasileira. \\
\hline Assunto & Ficçāo brasileira. \\
\hline Assunto & Judeus - Fiç̧ăo. \\
\hline Assunto & Exclusão social - Fiç̧õo. \\
\hline Assunto & Individualismo - Ficçầo. \\
\hline Assunto & Animais mitologicos - Ficção. \\
\hline
\end{tabular}

Fonte: Catálogo da Unesp 
Na análise e avaliação dos registros foram usados os mesmos critérios da primeira etapa da avaliação com acréscimo da etapa de comparação dos registros originais com os reindexados.

Após a reindexação dos registros bibliográficos, solicitou-se aos indexadores que respondessem a um novo questionário, cujo objetivo era avaliar a satisfação dos catalogadores com as adequações realizadas no Modelo de Indexação de Ficção (MENTIF) para uso na Rede de Bibliotecas da Unesp.

O questionário (Apêndice $C$ ) compôs-se, além da identificação do participante, de: pergunta fechada com filtro que direciona o catalogador a uma pergunta de múltipla escolha, e uma pergunta aberta final, solicitando comentários dos catalogadores sobre o MENTIF. O questionário foi disponibilizado na plataforma Formulários Google, e o link para participação foi enviado aos catalogadores selecionados da Rede de Bibliotecas da Unesp por meio de e-mail enviado pela Coordenadoria Geral de Bibliotecas.

\section{Discussão dos resultados para adequação do Modelo para Indexação de Ficção (MENTIF)}

As quatro etapas da Avaliação foram analisadas partindo do principal objetivo de realizar a necessária adequação do Modelo para Indexação de Ficção (MENTIF) utilizado por catalogadores, e ainda averiguar se: o MENTIF estava sendo utilizado após capacitações realizadas em 2014; haveria necessidade de mais treinamento, e identificar quais os catalogadores proficientes e os não proficientes em indexação de ficção.

Considerando-se as quatro etapas de avaliação, os resultados obtidos foram analisados e deram subsídios à realização de cada uma de modo subsequente. Os resultados das duas primeiras etapas, análise dos registros bibliográficos e das respostas ao primeiro questionário aplicado, proporcionaram ao Grupo de Política de Indexação elementos para o desenvolvimento da adequação do Modelo para Indexação de Ficção (MENTIF), cuja proposta pode ser avaliada nas etapas 3 e 4 com o apoio dos registros bibliográficos reindexados e das respostas sobre satisfação e insatisfação sobre a adequação do MENTIF.

Os resultados da primeira etapa revelaram que, dos 336 registros analisados em 2016, 110 registros não atenderam o padrão estabelecido pelo MENTIF, o que equivale a aproximadamente $32,7 \%$. Por outro lado, $2 / 3$ dos registros atenderam o MENTIF por meio da atribuição de gênero literário e localização geográfica (como por exemplo: gênero e localização geográfica, gênero ficção e localização geográfica, gênero de ficção específico) e assuntos/temas (assuntos específicos seguidos ou não da forma de ficção).

Observaram-se as seguintes ocorrências nos registros em desacordo com o MENTIF:

- Uso do termo mais genérico (Literatura, Ficção) apenas para atingir o mínimo de 3 termos estabelecido pela política de indexação, o que demonstrou claramente a não aplicação do modelo, visto que este proporciona a identificação de mais termos específicos para a representação do conteúdo e evitaria o uso de termos mais genéricos;

- Uso do "assunto na literatura". Exemplo: Mulheres na literatura. De acordo com 
nota nos registros de autoridade da Library of Congress Subject Headings (LCSH), o termo seguido da expressão "na literatura" deve ser utilizado apenas em obras teóricas ou de crítica; não deve ser usado para ficção, porém o grupo considerou, a princípio, que o catalogador analisou o assunto da obra e não utilizou o termo correto por falta de instrução a respeito;

- Uso indevido do tipo/categoria do material como assunto. Exemplo: Livros ilustrados para crianças, Livros para cegos.

Em relação aos catalogadores, ressalta-se que, dos 22 avaliados, 50\% foram proficientes, atingindo índices inferiores a $20 \%$ de registros que não atenderam o MENTIF. Cabe destacar que 5 catalogadores aplicaram o MENTIF em todos os registros avaliados, perfazendo $22 \%$, como se pode observar na Figura 3 .

\section{Figura 3. Porcentagem dos registros que não atendem o MENTIF referente ao total analisado por indexador}

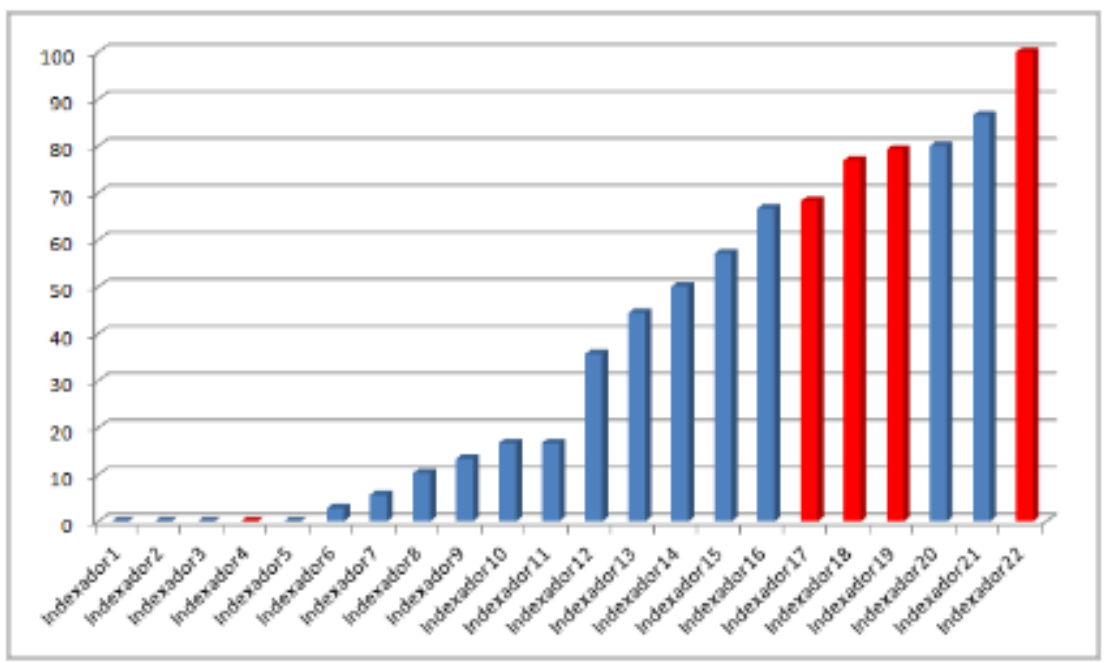

Fonte: Os autores.

Por outro lado, observa-se na Figura 3 que cinco catalogadores atingiram índices superiores a $70 \%$ de não atendimento do modelo e um deles atingiu $100 \%$ de incompatibilidade com o MENTIF. As colunas em vermelho indicam os catalogadores não participantes da capacitação. Entre os que tiveram mais de $70 \%$ dos seus registros em desacordo com o modelo, 60\% deles não participaram da capacitação (3 profissionais). É interessante destacar que um catalogador, mesmo não tendo participado da capacitação, teve $100 \%$ dos seus registros em acordo com o MENTIF. No entanto, ele teve apenas 2 registros analisados.

A análise dos resultados da primeira etapa motivou o envio do primeiro questionário cujas respostas iniciaram a segunda etapa de avaliação e serviram como base para o Grupo de Política de Indexação desenvolver a adequação do MENTIF para a Rede de Bibliotecas da Unesp. Dos 22 catalogadores avaliados, 54\% enviaram suas respostas por meio de formulário eletrônico. 
Quanto aos procedimentos de análise descritos pelos catalogadores (questão 1 do questionário), observou-se que as descrições apresentadas são, em sua maioria, diferentes dos procedimentos propostos no MENTIF, constituídos de seis passos para análise do texto de fiç̧ão - identificação da estrutura textual, leitura documentária (poderiam ser citados a leitura de título, subtítulo, sumário, resumo, quarta capa, orelhas, ilustrações, etc.), leitura do primeiro e último capítulo, identificação das categorias personagem, evento, espaço e tempo, a seleção dos conceitos e a tradução para a linguagem adotada (Linguagem Unesp).

Nenhum dos 10 catalogadores indicou completamente os procedimentos do MENTIF, porém um deles descreveu satisfatoriamente os procedimentos principais do modelo, mesmo sem tê-los descritos completamente. Quatro catalogadores atenderam parcialmente aos procedimentos indicados no MENTIF, descrevendo realizar até três passos dos seis principais que são indicados. De modo que cinco catalogadores não descreveram nenhuma etapa constante do procedimento indicado no MENTIF, dentre estes respondentes foi identificada também a existência de um padrão de análise compartilhado por dois catalogadores, que o descreveram de modo bastante semelhante.

Portanto, é seguro dizer que o uso do MENTIF atualmente é exceção entre os catalogadores. Esses resultados indicam a necessidade de novos treinamentos para capacitação dos catalogadores e a disponibilização de instruções complementares para o uso da metodologia. Quanto à necessidade de adequação do modelo, verificou-se a possibilidade de inclusão de consulta a orelhas e contracapa, indicado por seis catalogadores como fonte de informação para identificação de conceitos no documento, bem como indicação de resenhas e resumos em sites confiáveis na internet, caso seja necessário para complementar a identificação e seleção de conceitos.

Quanto à satisfação dos indexadores (Questão 2 do questionário), dos 12 que responderam às perguntas, apenas 3 apontaram insatisfações. Foram apontados como pontos de satisfação do MENTIF: facilitar, por meio das categorias (personagem, evento, espaço e tempo), a identificação de conceitos para termos específicos; promover uma aproximação mais adequada de conceitos relevantes tratados no texto de ficção; permitir maior eficiência na representação do documento, com termos mais específicos e melhor leitura e análise das obras para identificar os conceitos.

A insatisfação foi representada, principalmente, pelos seguintes problemas:

- Dificuldade de localização e/ou não existência das partes da estrutura textual da obra de ficção indicadas pelo MENTIF, seja pela própria estrutura de uma obra de ficção, seja pelo estado de conservação do material, caso de muitas obras antigas e já encadernadas, onde não seria possível extrair informações relevantes; insuficiência de informações no questionamento para os conceitos que se devem identificar nas categorias de personagens e eventos;

- Ausência da indicação das partes da estrutura textual onde podem ser localizados os conceitos de cada categoria;

- Inexistência de esclarecimentos no Manual de Política de Indexação para as Bibliotecas Universitárias da Unesp (2014) (Universidade Estadual Paulista "Júlio de 
Mesquita Filho", 2014) quanto à representação da forma ficcional, por exemplo,Ficção policial.

Outras indicações de insatisfação referem-se à: estrutura da obra de ficção, leitura de várias partes da obra de ficção, falta de tempo para a tarefa, não localização do termo autorizado na linguagem de indexação, inexistência de orientações formais para uso do MENTIF, contos e poemas não são previstos pelo MENTIF; incompreensão da linguagem da obra de ficção.

As dificuldades existentes na indexação de obras de ficção concentraram-se, em sua maior parte, relacionada à natureza da obra de ficção e na pouca familiaridade do profissional com esse tipo de material no ambiente de trabalho por não se tratar de uma obra didática ou científica.

Com os resultados dessas duas etapas da avaliação, o Grupo de Política de Indexação desenvolveu a proposta de adequação do MENTIF a partir das respostas do primeiro questionário aplicado na segunda etapa. A versão adaptada do Modelo para Indexação de Ficção (Quadro 3), aplicada em curso de capacitação dos catalogadores, foi aprimorada a partir de respostas obtidas pelo segundo questionário aplicado na quarta etapa e a partir do relato de dúvidas dos catalogadores durante o curso de capacitação.

Quadro 3. Modelo para Indexação de Ficção (versão adaptada)

\begin{tabular}{|c|c|c|c|c|}
\hline $\begin{array}{l}\text { Categorias } \\
\text { (primeira } \\
\text { coluna) }\end{array}$ & $\begin{array}{l}\text { Questionamento } \\
\text { (segunda coluna) }\end{array}$ & $\begin{array}{l}\text { Partes da } \\
\text { estrutura } \\
\text { textual } \\
\text { (terceira } \\
\text { coluna) }\end{array}$ & $\begin{array}{l}\text { Identificação } \\
\text { de conceitos } \\
\text { (orientado } \\
\text { pelo } \\
\text { conteúdo) } \\
\text { (quarta } \\
\text { coluna) }\end{array}$ & $\begin{array}{l}\text { Seleção de } \\
\text { conceitos } \\
\text { (orientado } \\
\text { pelo uso) } \\
\text { (quinta } \\
\text { coluna) }\end{array}$ \\
\hline Personagem & $\begin{array}{l}\text { Existem seres ou atores } \\
\text { que existem e participam } \\
\text { no mundo da ficção } \\
\text { (inclui o narrador quando } \\
\text { for o caso)? } \\
\text { Observação: } \\
\text { Seres (animados, } \\
\text { inanimados, imaginários: } \\
\text { pessoa, animal, pedra, } \\
\text { fantasma, etc.). } \\
\text { Características dos seres } \\
\text { que merecem destaque } \\
\text { (classe, gênero, } \\
\text { profissão, personalidade, } \\
\text { nacionalidade; quando } \\
\text { ligado a evento histórico } \\
\text { identificar nome } \\
\text { pessoal). }\end{array}$ & $\begin{array}{l}\text { Capa e } \\
\text { contracapa; } \\
\text { primeiro } \\
\text { capítulo; } \\
\text { último } \\
\text { capítulo. }\end{array}$ & & \\
\hline Evento & $\begin{array}{l}\text { Existem ocorrências e } \\
\text { acontecimentos do } \\
\text { mundo real e não real } \\
\text { (inclui atos humanos e }\end{array}$ & $\begin{array}{l}\text { primeiro e } \\
\text { segundo } \\
\text { capítulos; } \\
\text { resenhas. }\end{array}$ & & \\
\hline
\end{tabular}




\begin{tabular}{|l|l|l|l|l|}
\hline & $\begin{array}{l}\text { não humanos)? } \\
\text { Observações: } \\
\text { Ocorrências e } \\
\text { acontecimentos (fatos, } \\
\text { ações, fenômenos } \\
\text { naturais, sobrenaturais, } \\
\text { situações, cerimônias, } \\
\text { relacionamentos, } \\
\text { sentimentos, etc.). }\end{array}$ & & & \\
\hline Espaço & $\begin{array}{l}\text { A narração acontece em } \\
\text { um determinado lugar } \\
\text { geográfico ou localização } \\
\text { (ou ambiente) no mundo } \\
\text { ficcional? }\end{array}$ & $\begin{array}{l}\text { Orelhas; } \\
\text { primeiro } \\
\text { capítulo; } \\
\text { resenhas. }\end{array}$ & & \\
\hline Tempo & $\begin{array}{l}\text { Existe uma unidade de } \\
\text { tempo no mundo } \\
\text { ficcional? } \\
\text { Observação: }\end{array}$ & $\begin{array}{l}\text { Orelhas; } \\
\text { primeiro } \\
\text { capítulo; } \\
\text { resenhas. } \\
\text { (período de tempo }\end{array}$ & & \\
específico). & & & \\
\end{tabular}

Fonte: Adaptado de Sabbag, 2017

As adequações do MENTIF foram realizadas com objetivo de resolver os problemas apontados nas respostas do primeiro questionário aplicado. Portanto, foram incluídas, após cada questionamento na segunda coluna, orientações de quais características deveriam ser observadas relacionadas às respectivas categorias para resolver o problema de incompreensão do uso das categorias personagem, evento, espaço e tempo; e foi incluída a terceira coluna partes da estrutura textual, que não existia no modelo inicial, para orientar o catalogador sobre a localização do conceito em partes da estrutura textual, diminuir o tempo de indexação e garantir a identificação correta dos conceitos.

Para orientação metodológica desta versão adaptada do MENTIF (Quadro 3), o Grupo de Política de Indexação trabalhou na adequação das orientações propostas por Sabbag (2017), e propôs o documento Orientações para uso do Modelo para Indexação de Fiç̧ão, versão adaptada (Apêndice B). Essas adaptações consistiram de:

1. Na fase de identificação da tipologia textual: esclarecimento na identificação da obra de ficção, exemplificando os tipos de materiais que não deveriam ser indexados através do modelo por possuírem diversos temas ou consistirem em outros métodos, tais como contos, filmes, poesias, crônicas, coletâneas, peças de teatro e cartas;

2. Na fase de leitura documentária: inclusão de outras partes textuais (capa, contracapa e orelha) para identificação dos conceitos, bem como orientação para uso de fontes de informação na internet, como resenhas, resumos, etc.;

3. Na fase de identificação dos conceitos: esclarecimento, através de questionamento, nas categorias personagem (quem, com quem, o que), evento (o que aconteceu), espaço (onde aconteceu) e tempo (quando aconteceu), de quais características deveriam ser observadas; inclusão de uma coluna com as partes da estrutura textual para auxiliar na identificação dos conceitos; 
4. Na fase de seleção dos conceitos: orientação para que o catalogador pense no uso que os conceitos selecionados terão para a comunidade usuária;

5. Na fase da representação documentária: inclusão de exemplos práticos para auxiliar a representação dos conceitos na Linguagem Unesp.

A versão com adequação do Modelo para Indexação de Ficção e de suas orientações foi apresentada e aplicada em capacitação dos catalogadores que puderam utilizá-la na reindexação de registros bibliográficos selecionados. A avaliação desses registros demonstrou concordância com o MENTIF e suas orientações. Ficou evidente, na comparação entre registros anteriores e posteriores à adequação, o aumento de termos específicos em cada um dos registros bibliográficos reindexados.

O feedback dos catalogadores após a reindexação dos registros posterior a capacitação de 2017 e aplicação do questionário (terceira e quarta etapas) foi positivo. Percebeu-se que os motivos de insatisfação apontados anteriormente não predominaram desta vez. Entretanto, o fator tempo foi bastante mencionado e alguns catalogadores atribuíram esse problema à falta de funcionários em suas bibliotecas, fato que dificultaria o uso do modelo. Porém, isso caracteriza um problema da instituição e não do MENTIF.

O Grupo de Política de Indexação analisou todas as questões e também o desempenho dos catalogadores nos exercícios realizados durante a capacitação e percebeu que muitos catalogadores utilizaram termos da Linguagem Unesp ainda na fase da seleção dos conceitos e, por esse motivo, decidiu pela inclusão de uma observação sobre o assunto no texto das Orientações para uso do MENTIF, versão adaptada, a saber: "Não confundir essa etapa com a Representação Documentária. Neste momento a Linguagem Unesp ainda não precisa ser consultada".

\section{Considerações finais}

Diante da necessidade de aperfeiçoar a representação das obras de ficção com ampliação de pontos de acesso por assunto de temas específicos, realizamos pesquisa para avaliação do Modelo para Indexação de Ficção (MENTIF) com objetivo de realizar adequações necessárias para sua aplicação em bibliotecas universitárias.

Após capacitação dos catalogadores das bibliotecas universitárias da Unesp e uso do MENTIF por um período de dois anos, foi aplicada metodologia de avaliação realizada em quatro etapas, no intuito de verificar sua aplicabilidade na indexação e levantar indicações de satisfação e insatisfação. Os resultados obtidos demonstraram que o modelo era utilizado pelos catalogadores e adequações necessárias foram indicadas e realizadas, em sua estrutura e em suas orientações, para ajustar-se à política de indexação com inclusão de diretrizes sobre o uso da linguagem de indexação de ficção.

O uso da versão adaptada do modelo e de suas orientações passou por avaliação final, constatando que houve retorno positivo dos catalogadores em relação ao uso da metodologia de indexação proposta e aumento da atribuição de termos específicos às obras indexadas. Constatou-se, também, que algumas dificuldades persistiram em relação ao uso do MENTIF, em especial quanto ao tempo demandado para a análise da obra, porém, consideramos que o procedimento requer um tempo de adaptação e internalização 
do processo, após o qual, se torna conhecimento internalizado do catalogador, quem o fará intuitivamente.

O modelo propiciou aos bibliotecários catalogadores da Rede de Bibliotecas da Unesp o aprimoramento da metodologia de indexação das obras de ficção, no que tange à identificação de novos termos e a forma cognitiva de aplicá-los na catalogação de assunto.

A metodologia empregada no MENTIF proporciona a representação de assuntos específicos referentes ao conteúdo das narrativas ficcionais, possibilitando uma recuperação pelos assuntos particulares destas obras, diferentemente do que vinha ocorrendo com a atribuição apenas de termos referentes à forma e nacionalidade da obra.

Finalmente, a avaliação e adequação do modelo para indexação de ficção (MENTIF) proporcionou uma reflexão profícua entre a teoria e a prática que possibilitou que os conceitos teóricos e metodológicos elaborados na construção do modelo fossem testados por profissionais proficientes. Essa oportunidade pragmática permitiu que os conhecimentos teóricos, combinados com a experiência prática, resolvessem questões mais abrangentes do fazer profissional mediante reelaboração intelectual caracterizada pela formulação de novas ideias (adequação do modelo) com importantes contribuições para a epistemologia do saber-como.

Como resultado dessa prática compartilhada, novos elementos podem ser incorporados à metodologia de indexação original, que não pretende ser uma metodologia acabada, mas aberta a novos desenvolvimentos, pragmáticos e teóricos, que contribuam para o preenchimento de possíveis lacunas.

O modelo metodológico para indexação de ficção representa mais um passo dado no desenvolvimento de metodologias de indexação direcionadas a tipologias textuais diversas, a exemplo dos modelos metodológicos para indexação de livros e de artigos científicos, resultados de pesquisas realizadas em função das ações científicas do Grupo de Pesquisa "Representação Temática da Informação". Ressalta-se, por conseguinte, o caráter inovador desta experiência que assegura, por meio do aperfeiçoamento do tratamento temático da informação, resultados metodológicos uniformes para a atuação do catalogador na gestão da informação.

\section{Notas}

1 Grupo constituído com pesquisadores, catalogadores de bibliotecas universitárias e bolsistas de iniciação científica e de pós-graduação e institucionalizado pela Portaria CGB/UNESP no 02 de 12 de março de 2015 que desenvolveu e avalia a política de indexação da rede de bibliotecas universitárias da UNESP.

\section{Referências}

Andersson, R., \& Holst, E. (1996). Indexes and other depictions of fiction: a new model for analysis empirically tested. Svensk Biblioteksforskning/Swedish Library Research, 2-3, 7795. 
Baker, E. A. (1899). The classification of fiction. Library World, 1(11), 198-200.

Beghtol, C. (1986). Bibliographic classification theory and text linguistics: about ness analysis, intertextuality and the cognitive act of classifying documents. Journal of documentation, 42(2), 84-113. https://dx.doi.org/10.1108/eb026788

Beghtol, C. (1989). Access to fiction: a problem in classification theory and practice, part 1. International Classification, 16(3), 134-140.

Beghtol, C. (1992). Toward a theory of fiction analysis for information storage and retrieval. Proc. 5th Int. Study Conf. On Classification Research, Toronto, Canada, 6, 24-28. Amsterdam: Elsevier.

Beghtol, C. (1994a). Domain analysis, literary warrant, and consensus: the case offiction studies. Journal of the American Society for Information Science, 46(1), 30-44.

Beghtol, C. (1994b). The classification of fiction: the development of system based on theoretical principles. Metuchen: Scarecrow.

Beghtol, C. (1997). Stories: applications of narrative discourse analysis to issues in information storage and retrieval. Knowledge Organization, 24(2), 64-71.

Bell, H. K. (1991). Indexing fiction: a story of complexity. The Indexer, 17(4), October. Recuperado de https://www.theindexer.org/files/17-4/17-4_251.pdf

Brewer, W. F. (1984). The story schema: universal and culture-specific properties. Em Literacy, language and learning: the nature and consequences of reading and writing. Cambridge: Cambridge University Press. Recuperado de https://www.ideals.illinois.edu/bitstream/handle/2142/17673/ctrstreadtechrepv01984i003 22 opt.pdf?sequence $=1$

Burgess, L. A. (1936). A system for the classification and evaluation of fiction. The library world, 38.

Eriksson, R. (2005). The classification and indexing of imaginative literature. Charlotte: NC.

Fiorin, J. L. (2011). Elementos de análise do discurso. $15^{\circ}$ ed. São Paulo: Contexto.

García-Marco, F. J. et al. (2010). Knowledge organization on fiction and narrative documents: a challenge in the age of multimedia revolutions. Em C. Gnolli \& F. Mazzocchi (Org.), Paradigms and conceptual systems in knowledge organization. (pp. 262-268). Wurzburg: Ergon

Guimarães, J. A. C., Moraes, J. B. E., Guarido, e M. D. M. (2007). Analisis documental de contenido de textos narrativos: bases espistemológicas y perspectivas metodológicas. Em F. J. García-Marco (Org.), Avances y perspectivas en sistemas de información y documentación en entorno digital (pp. 93-100). Zaragoza: Prensas Universitarias de Zaragoza.

Harrel, G. (1985). The classification and organization of adult fiction in large American public libraries. Public Libraries, 24(1), 13-14. 
Hayes, S. (1992). Enhanced catalog access to fiction: a preliminary study. Library resources \& technical services, 36(4), 441-459.

Hidderley, R., \& Rafferty, P. (1997). Democratic indexing: an approach to the retrieval of fiction. Information Services and Use, 17(2-3), 101-109.

Jansson, E., \& Sodervall, B. (1987). Tesaurus for index eringavsk on litteratur. Boras: Hogsk.

Lancaster, F. W. (2004). Indexação e resumos. Brasília DF: Briquet de Lemos.

Macpherson, R. (1987). Children's literature indexes atmora y house. Library Review, 36(4), 254-260. https://dx.doi.org/10.1108/eb012850

Moraes, J. B. E. de (2011). A questão do about ness no texto narrativo de ficção: perspectivas metodológicas para a Ciência da Informação. 2011. 81f (Tese LivreDocência). Faculdade de Filosofia e Ciências de Marília, Universidade Estadual, Marília.

Negrini, G. (1995). Thesaurus di letteratura italiana: aggiornamento al 30 dicembre 1994. Roma: C.N.R.

Nielson, H. J. (1997). The nature of fiction and its significance for classification and indexing. Information Services and Use, 17(2-3), 171-182.

Olderr, S. (1991). Olderr's fiction subject headings: a supplement and guide to the LC thesaurus. Chicago: American Library Association.

Pejtersen, A. M., \& Austin, J. (1983). Fiction retrieval: experimental design and evaluation of a search system based on user' value criteria (part 1). Journal of documentation, 39(4), 230-246. https://dx.doi.org/10.1108/eb026750

Rafferty, P. (2001). The representation of knowledge in library classification schemes. Knowledge Organization, 28(4), 180-191. Recuperado de https://www.academia.edu/494322/The representation_of knowledge in library classific ation_schemes

Ranta, J. (1991). The new literary scholarship and a basis for increased subject catalog access to imaginative literature. Journal of librarianship and information science, 3-26. https://dx.doi.org/10.1300/J104v14n01 02

Ruthrof, H. (1981). The reader's construction of narrative. London: Routledge \& Kegan Paul.

Saarti, J. (1997). Feeding with the spoon, or the effects of shelf classification of fiction on the loaning of fiction. Information Services \& Use, 17(2-3), 159-169.

Saarti, J. (1999a). Fiction indexing and the development of fiction thesauri. Journal of Librarianship and Information Science, 31(2), 85-92. https://dx.doi.org/10.1177/096100069903100203

Saarti, J. (1999b). Aspects of fiction alliterature content description: consistency of the abstracts and subject indexing of novels by public library professionals and client (in finnish). (Ph. D. thesis). University of Oulu. 
Saarti, J. (2002). Consistency of subject indexing of novels by public library professionals and patrons. Journal of Documentation, 58(1), 49-65. https://dx.doi.org/10.1108/00220410210425403

Sabbag, D. (2017). Orientações para uso do MENTIF (Metodologia para Indexação de Ficção). Em Universidade Estadual Paulista (Unesp). (2014) Coordenadoria Geral de Bibliotecas (2017). Manual de política de indexação para as bibliotecas universitárias da Unesp [recurso eletrônico] / coordenação: Mariângela Spotti Lopes Fujita. $1^{\circ}$ ed. rev. e ampl (pp.19-21). São Paulo: Unesp. Recuperado de https://www.biblioteca.unesp.br/portal/arquivos/manual-politica-indexacao-2017.pdf

Sabbag, D. M. A. (2013). Análise documental em textos narrativos de ficção: subsídios para o processo de análise (Tese de Doutorado). Universidade Estadual Paulista "Júlio de Mesquita Filho", Faculdade de Filosofia e Ciências, Marília, São Paulo. Recuperado de https://repositorio.unesp.br/handle/11449/103384

Spiller, D. (1980). The provision of fiction for publiclibraries. Journal of librarianship and information, 1 , October. Recuperado de http://journals.sagepub.com/doi/pdf/10.1177/096100068001200404

Tatit, L. (2007). Abordagem do texto. Em J. L. Fiorin (Org),Introdução à linguística: I: objetos teóricos (pp. 187-209). São Paulo: Contexto.

Universidade Estadual Paulista - Unesp (2014). Coordenadoria Geral de Bibliotecas (2017). Manual de política de indexação para as bibliotecas universitárias da Unesp [recurso eletrônico] / coordenação: Mariângela Spotti Lopes Fujita. $1^{\circ}$ ed. rev. e ampl. São Paulo: Unesp. Recuperado de https://www.biblioteca.unesp.br/portal/arquivos/manual-depolitica-de-indexacao.pdf

Universidade Estadual Paulista - Unesp (2017). Coordenadoria Geral de Bibliotecas (2017). Manual de política de indexação para as bibliotecas universitárias da Unesp [recurso eletrônico] / coordenação: Mariângela Spotti Lopes Fujita. $1^{\circ}$ ed. rev. e ampl. São Paulo: Unesp. Recuperado de https://www.biblioteca.unesp.br/portal/arquivos/manualpolitica-indexacao-2017.pdf 